\title{
Infertility caused by male partners with genetic defects in Sichuan Province of China
}

\author{
Q. Quann ${ }^{1,2}$, T.J. Li ${ }^{1,2}$, X.P. Ding ${ }^{1,2}$, J. Wei ${ }^{2}$, L.X. Li $^{2}$ and L. Fu ${ }^{2}$ \\ ${ }^{1}$ Bio-Resource Research and Utilization Joint Key Laboratory of Sichuan-Chongqing, \\ Institute of Medical Genetics, School of Life Science, Sichuan University, \\ Chengdu, China \\ ${ }^{2}$ Institute of Medical Genetics, School of Life Science, Sichuan University, \\ Chengdu, China \\ Corresponding author: X.P. Ding \\ E-mail: Brainding@scu.edu.cn
}

Genet. Mol. Res. 12 (4): 6512-6520 (2013)

Received April 5, 2013

Accepted September 22, 2013

Published December 11, 2013

DOI http://dx.doi.org/10.4238/2013.December.11.2

\begin{abstract}
The purpose of this study was to detect chromosomal aberrations and azoospermia factor (AZF) microdeletions in male patients with reproductive problems and to summarize related clinical features to provide reliable information for evaluating prenatal and preimplantation diagnoses. A large cohort of 5083 men with various phenotypes of male infertility was analyzed via G-banding karyotyping, and Origin 8.0 was used to analyze the prevalence of abnormalities. Additionally, patients with azoospermia, oligozoospermia, and oligoasthenozoospermia were analyzed using multiplex polymerase chain reaction to detect microdeletion in the AZF. We identified 387 patients with abnormal karyotypes, and the ratio was $7.61 \%$. Among them were 175 patients with Klinefelter's syndrome, which was the most common numerical chromosomal abnormality and accounted for $45.22 \%$ of all chromosomal aberrations. The frequencies of increased satellites, balanced translocations, and Robertsonian translocations were $6.47,7.00$, and $3.62 \%$, respectively. Multiplex polymerase chain reaction performed in 810 cases with azoospermia, oligozoospermia, and oligoasthenozoospermia found a ratio of AZF microdeletions of $4.94 \%$. The finding suggests that chromosomal
\end{abstract}


abnormalities and AZF deletion are main factors that result in male infertility. Detecting these common genetic variations is necessary in infertile men seeking assisted reproductive technology.

Key words: Male infertility; Klinefelter's syndrome; Chromosome; Prenatal diagnosis; Preimplantation genetic diagnosis

\section{INTRODUCTION}

According to the World Health Organization, infertility affects approximately 1 in 6 couples worldwide, and male factor infertility accounts for an estimated half of all infertility cases. Male infertility occurs because of various factors, including those of environmental and genetic origin. The most common genetic causes of male infertility are chromosomal abnormalities and Y chromosome microdeletions, which often result in azoospermia (AS) or oligozoospermia (OS). Among patients with chromosomal aberrations, Klinefelter's syndrome is the most frequent cause of infertility, affecting nearly $4 \%$ of infertile men and resulting in significant financial and emotional costs.

Assisted reproductive technology (ART) is widely used to help infertile men produce healthy offspring. Therefore, determining the exact genetic defects in infertile patients is critical to evaluating the risks of ART. The aim of this study was to investigate the frequencies of various chromosomal abnormalities and $\mathrm{Y}$ chromosome microdeletions in patients with AS, OS, and oligoasthenozoospermia (OAT) in Sichuan Province, China. The results of this study provide valuable information for improving the diagnosis of male infertility and developing appropriate therapies for infertile men in that region.

\section{MATERIAL AND METHODS}

\section{Subjects}

A total of 5083 male patients with reproductive problems diagnosed at the Affiliate Hospital of Sichuan Genitalia Hygiene Research Center (Chengdu, China) between September 2010 and May 2012 were recruited for this study. All patients lived in Sichuan Province at the time of the study. The study was approved by the ethics committee of Sichuan University.

\section{Karyotype analysis}

Karyotyping was performed using standard G-banding. Briefly, peripheral blood lymphocytes were cultured for $72 \mathrm{~h}$ in RPMI-1640 with phytohemagglutinin and fetal bovine serum. Two hours before the completion of culturing, colcemid was added to the medium. G-banding of metaphase chromosomes was performed using Giemsa staining. At least 20 metaphase spreads were analyzed for each patient, and at least 50 metaphase spreads were analyzed to confirm abnormalities.

\section{Semen analysis}

Conventional semen analysis was performed in patients with Klinefelter's syndrome according to World Health Organization guidelines. 


\section{Detection of azoospermia factor (AZF) microdeletions}

Multiplex polymerase chain reaction was performed to detect microdeletions in the AZF region for patients with AS, OS, and OAT. Genomic DNA was extracted from peripheral blood lymphocytes using an H.Q. \& Q. Blood DNA Kit. Using previous studies in the Chinese population and the diagnostic criteria of European Academy of Andrology, we chose 6 sequence-tagged site (STS) markers in the AZF region to detect microdeletions: sY86 and USP9Y in AZFa, sY127 and sY134 in AZFb, and sY254 and sY255 in AZFc. Additionally, the SRY (sY14; sex-determining region on Y) was used as an internal control, and deionized water and female samples were used as positive and negative controls, respectively. Two multiplex polymerase chain reaction experiments were designed as follows: multiplex 1 contained STSs markers for USP9Y, sY134, and sY255, and multiplex2 contained STS markers for SRY, sY86, sY127, and sY254.

\section{Statistical analysis}

Data management and statistical analysis were carried out using Origin 8.0.

\section{RESULTS}

The results of the study revealed that $387(7.61 \%)$ of all patients $(\mathrm{N}=5083)$ had chromosomal abnormalities, as shown in Table 1. Available karyotypes and clinical characteristics are summarized in Figure 1. Among patients with abnormalities, sex chromosome and autosomal chromosome aberrations accounted for 76.75 and $21.96 \%$, respectively. Additionally, we identified $4(1.03 \%)$ patients with complicated translocations between sex and autosomal chromosomes and $8(2.07 \%)$ patients with sex reversal. Klinefelter's syndrome was the most common chromosomal aneuploidy, with 175 cases accounting for $45.22 \%$ of all chromosomal aberrations. The number of subjects with increased satellites, balanced translocations, and Robertsonian translocations was 25 (6.46\%), 27 (7.00\%), and 14 (3.62\%), respectively. Chromosomal variants were found in all chromosomes except 4 and 20, whereas chromosomes 1 , 13-15, and $\mathrm{Y}$ displayed higher frequencies of abnormalities (Figure 2).

\section{DISCUSSION}

According to our data, the main causes of male infertility are chromosomal abnormalities, including structural and numerical aberrations. We identified 175 patients with Klinefelter's syndrome, which accounted for the majority of the abnormalities. The incidence of Klinefelter's syndrome in infertile men was $3.42 \%$, which agrees with previously published data (Guichaoua et al., 1993). Increased satellites, balanced translocations, and Robertsonian translocations were the most common autosomal chromosomal abnormalities leading to male infertility.

Klinefelter's syndrome is the most common chromosomal aneuploidy leading to male infertility (Lanfranco et al., 2004), and our study reconfirmed this conclusion. The prevalence of Klinefelter's syndrome is $0.1-0.2 \%$ in the general population (Lanfranco et al., 2004), 3.1$4 \%$ in infertile male, and $11 \%$ in azoospermic men (Van Assche et al., 1996). Only an estimated $25 \%$ of individuals with Klinefelter's syndrome in the general population are diagnosed 
Table 1. Clinical features of 387 patients with chromosomal aberration.

\begin{tabular}{|c|c|c|c|}
\hline & Karyotpye & Total & Clinical feature \\
\hline \multicolumn{4}{|l|}{ Sex chromosome } \\
\hline \multicolumn{4}{|l|}{ Numerical abnormalities } \\
\hline & $45, \mathrm{X} 0 / 46, \mathrm{XY}$ & 2 & AS \\
\hline & $47, \mathrm{XXY}$ & 166 & $\begin{array}{l}\text { Small testis, gynecomastia, hypogonadism; } \\
\text { AS, OS, OAT }\end{array}$ \\
\hline & 47, XXY, 21ps + & 1 & $\begin{array}{l}\text { Small testis, gynecomastia, hypogonadism, } \\
\text { gonadal dysgenesis; AS, OS, }\end{array}$ \\
\hline & $47, \mathrm{XXY} / 46, \mathrm{XY}$ & 4 & OAT \\
\hline & $48, \mathrm{XXY},+\operatorname{der}$ & 1 & AS \\
\hline & $48, \mathrm{XXYY}$ & 2 & $\begin{array}{l}\text { Gynecomastia, hypogonadism, gonadal } \\
\text { dysgenesis; OS }\end{array}$ \\
\hline & 46, XX (43)/48, XXYY(7) & 1 & \\
\hline \multicolumn{4}{|l|}{ Structural abnormalities } \\
\hline & 46, XY, dup (Yp) & 1 & AS \\
\hline & $46, \mathrm{XY}, \mathrm{i}(\mathrm{Yq})$ & 2 & AS \\
\hline & $46, X Y, Y \geq 18$ & 55 & $\begin{array}{l}\text { Genital development defect, poor } \\
\text { maternal history; AS, OS, OAT }\end{array}$ \\
\hline & $46, X Y, Y \leq 21$ & 49 & Miscarriage; AS, OS, OAT \\
\hline & $46, \mathrm{XY}, \operatorname{del}(\mathrm{Yq})$ & 4 & AS \\
\hline & $46, \mathrm{XY}, \mathrm{t}(\mathrm{X} ; \mathrm{Y})$ & 1 & AS \\
\hline & $46, \mathrm{XY}, \mathrm{t}(\mathrm{Xq} ; \mathrm{Y})$ & 1 & AS \\
\hline \multirow{2}{*}{\multicolumn{4}{|c|}{$\begin{array}{l}\text { Autosomal chromosome } \\
\text { Numerical abnormalities }\end{array}$}} \\
\hline & & & \\
\hline & $45, \mathrm{XY}, \operatorname{rob}(13 ; 14)$ & 11 & Miscarriage, poor materal history \\
\hline \multicolumn{4}{|l|}{ Structural abnormalities } \\
\hline & $46, \mathrm{XY}, \operatorname{rob}(14 ; 21)$ & 1 & Miscarriage \\
\hline & $45, X Y, \operatorname{rob}(14 ; 14)$ & 1 & Miscarriage \\
\hline & $45, X Y, \operatorname{rob}(14 ; 15)$ & 1 & \\
\hline & $46, \mathrm{XY}, 1 \mathrm{ph}+$ & 1 & OAT \\
\hline & $46, \mathrm{XY}, 13 \mathrm{ps}+$ & 3 & \\
\hline & $46, \mathrm{XY}, 14 \mathrm{ps}^{+}$ & 4 & Poor materal history \\
\hline & $46, \mathrm{XY}, 15 \mathrm{ps}+$ & 9 & Fetal anomaly, AS \\
\hline & $46, \mathrm{XY}, 16 \mathrm{ps}+$ & 1 & \\
\hline & $46, \mathrm{XY}, 21 \mathrm{ps}+$ & 3 & AS \\
\hline & $46, \mathrm{XY}, 22 \mathrm{ps}+$ & 4 & AS \\
\hline & $46, \mathrm{XY}, 1 \mathrm{qh}+$ & 10 & Miscarriage \\
\hline & $46, \mathrm{XY}, 16 \mathrm{qh}+$ & 1 & Fetal anomaly \\
\hline & $46, \mathrm{XY}$, dup (1q12) & 5 & Poor maternal history \\
\hline & $46, \mathrm{XY}, \operatorname{dup}(9 \mathrm{p} 13)$ & 1 & \\
\hline & $46, X Y, \operatorname{dup}(9 \mathrm{p} 21)$ & 2 & Poor maternal history \\
\hline & 46, XY, dup (19) (pter $\rightarrow$ p13:p13 $\rightarrow$ p12::p13 $\rightarrow$ qter $)$ & 1 & Miscarriage \\
\hline & $46, X Y, \operatorname{inv}(1)$ & 1 & Miscarriage \\
\hline & $46, X Y, \operatorname{inv}(1 p)$ & 1 & Miscarriage \\
\hline & $46, X Y, \operatorname{inv}(9)$ & 2 & Poor maternal history \\
\hline & $46, X Y$, inv (21q) & 1 & Miscarriage \\
\hline & $46, \mathrm{XY}, \mathrm{t}(1 ; 11)$ & 2 & OAT \\
\hline & $46, \mathrm{XY}, \mathrm{t}(1 ; 12)$ & 1 & \\
\hline & $46, \mathrm{XY}, \mathrm{t}(1 ; 17)$ & 1 & \\
\hline & $46, \mathrm{XY}, \mathrm{t}(1 ; 5)$ & 2 & Miscarriage \\
\hline & $46, X Y, t(1 ; 7)$ & 2 & \\
\hline & $46, \mathrm{XY}, \mathrm{t}(1 ; 8)$ & 1 & Miscarriage \\
\hline & $46, \mathrm{XY}, \mathrm{t}(1 ; 9)$ & 1 & Miscarriage \\
\hline & $46, \mathrm{XY}, \mathrm{t}(2 ; 13)$ & 1 & \\
\hline & $46, \mathrm{XY}, \mathrm{t}(3 ; 15)$ & 1 & \\
\hline & $46, \mathrm{XY}, \mathrm{t}(5 ; 17)$ & 1 & Poor materal history \\
\hline & $46, \mathrm{XY}, \mathrm{t}(6 ; 14)$ & 1 & AS \\
\hline & $46, \mathrm{XY} / 46, \mathrm{XY}, \mathrm{t}(7 ; 13)(20 / 1)$ & 1 & AS \\
\hline & $46, \mathrm{XY} / 46, \mathrm{XY}, \mathrm{t}(8 \mathrm{p} ; \mathrm{q})(20 / 1)$ & 1 & OAT \\
\hline & $46, \mathrm{XY} / 46, \mathrm{XY}, \mathrm{t}(7 ; 14)(10 / 2)$ & 1 & OAT \\
\hline & $46, \mathrm{XY}, \mathrm{t}(15 ; 18)$ & 1 & AS \\
\hline & 46, XY, t (1q; 17p) & 1 & Miscarriage \\
\hline & $46, \mathrm{XY}, \mathrm{t}(2 ; 9 ; 18)$ & 1 & Miscarriage \\
\hline
\end{tabular}

Continued on next page 


\begin{tabular}{|c|c|c|c|}
\hline & Karyotpye & Total & Clinical feature \\
\hline \multirow{3}{*}{$\begin{array}{l}\text { Translocation between sex } \\
\text { chromosome and autosome }\end{array}$} & $\begin{array}{l}46, X Y, t(6 ; 19)(6 p t e r \rightarrow 6 q 22:: 19 q 14 \rightarrow 19 q \text { ter } \\
19 \text { pter } \rightarrow 19 q 14:: 6 q 22 \rightarrow 6 q t e r)\end{array}$ & 1 & \\
\hline & $46, \mathrm{XY}, \mathrm{t}(5 ; \mathrm{X})$ & 1 & AS \\
\hline & $46, \mathrm{XY}, \mathrm{t}(1 ; \mathrm{Y})$ & 1 & OAT \\
\hline \multirow{3}{*}{ Sex reversal } & $46, \mathrm{XY}, \mathrm{t}(13 ; \mathrm{Y})$ & 1 & AS \\
\hline & $46, \mathrm{XY}, \mathrm{t}(16 \mathrm{q} ; \mathrm{Xp})$ & 1 & AS \\
\hline & $46, \mathrm{XX}$ & $\begin{array}{r}8 \\
387\end{array}$ & Male phenotype, infertile, small testis \\
\hline
\end{tabular}

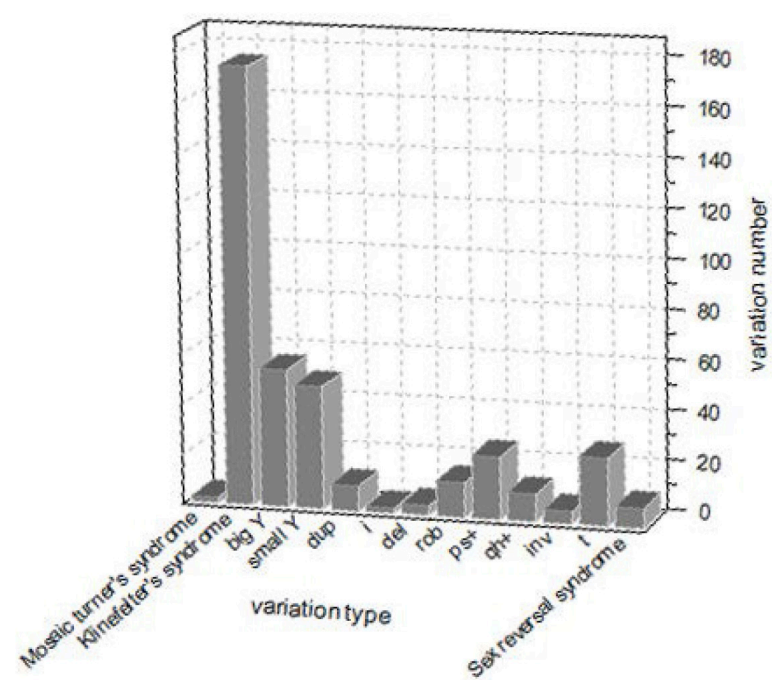

Figure 1. Types of chromosomal abnormality and prevalence, big Y meaning $\mathrm{Y} \geq 18$ Chromosome, small Ymeaning $\mathrm{Y} \leq 21$ Chromosome.

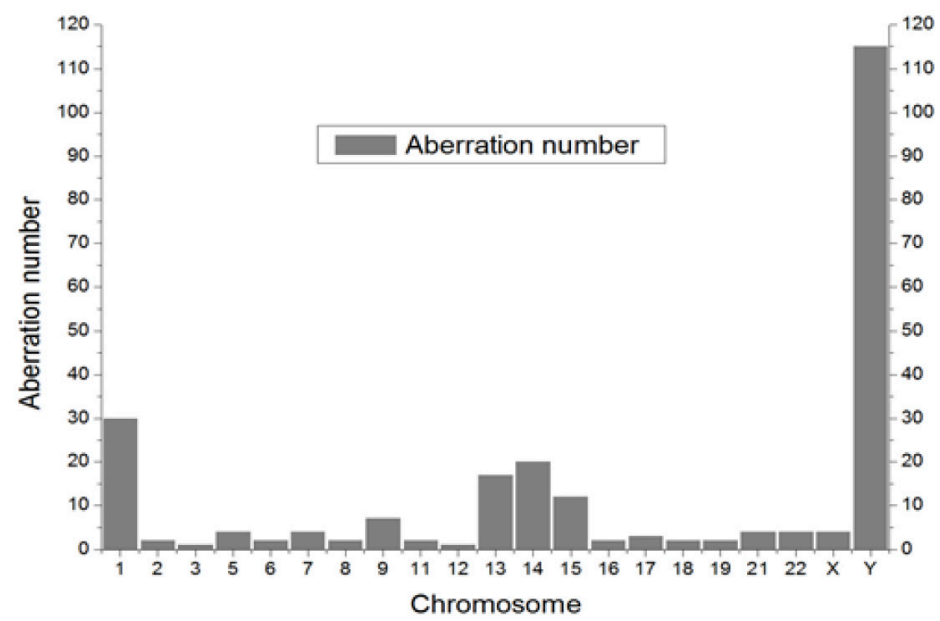

Figure 2. Distribution of abnormality in chromosomes (Klinefelter's syndrome was excluded). 
as such, and the syndrome is detected in only a limited number of individuals before puberty because physical anomalies are difficult to notice in children. The most common reported karyotype of Klinefelter's syndrome is non-mosaicism (47, XXY); mosaicism accounts for only $15 \%$ of all cases (Mitra et al., 2006). We identified 5 patients with mosaicism (2.86\%), which is a notable departure from published reports of 10\% (Staessen et al., 2003) and 15\% (Mitra et al., 2006). This difference may be due to sample size and study population variations. Patients may have also had inconsistencies in peripheral blood and gonadal karyotypes.

Our results showed that $27.43 \%$ of patients with Klinefelter's syndrome have sperm counts higher than $1 \times 10^{7} / \mathrm{mL}$, as show in Table 2 . This percentage is inconsistent with the conclusions of Reubinoff et al. (1998), who consider that non-mosaic Klinefelter's syndrome patients are generally azoospermic owing to primary testicular failure. We hope to launch more thorough research on this kind of patient to explore the reason. However, the sperm of these patients displayed abnormalities in both morphology and mobility, which may result from abnormal concentrations of follicle-stimulating hormone and luteinizing hormone and lower testosterone levels in the microenvironment for sperm genesis (Figure 3). Differences in physical qualities of patients and life habits may also contribute to variations in semen parameters.

\begin{tabular}{|c|c|c|}
\hline Sperm concentration $\left(10^{6} / \mathrm{mL}\right)^{\mathrm{a}}$ & $\mathrm{N}$ & Ratio (\%) \\
\hline 0 & 119 & 68 \\
\hline $0-10$ & 8 & 4.57 \\
\hline $10-50$ & 32 & 18.29 \\
\hline $50-100$ & 16 & 9.14 \\
\hline
\end{tabular}

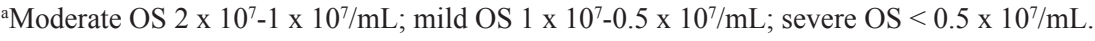

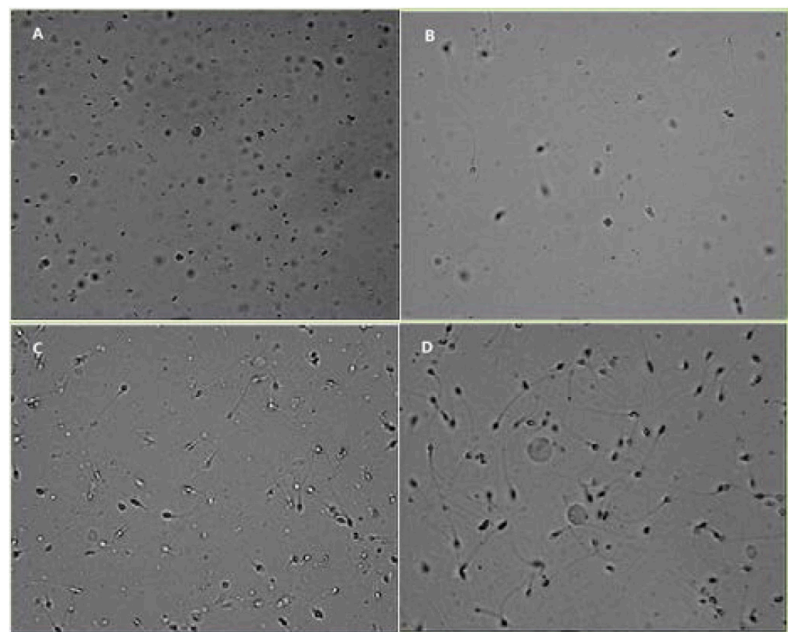

Figure 3. A. Klinefelter's Syndrome with no spermatozoon; B. Klinefelter's Syndrome with minimum spermatozoon density $=9.091 \times 10^{6} / \mathrm{mL} ;$ C. Klinefelter's Syndrome with maximum spermatozoon density $=57.046 \times 10^{6} / \mathrm{mL} ; \mathbf{D}$. Normal control part spermatozoon density $=69.389 \times 10^{6} / \mathrm{mL}$.

A syndrome known as $48, \mathrm{XXYY}$ is a rare karyotype of sex chromosome aneuploidy occurring at a rate of approximately 1 in 18,000 males (Tartaglia et al., 2009). Two 
subjects with this syndrome were identified in our study. The frequency of $48, \mathrm{XXYY}$ increases to 1 in 2500 in infertile men, so the higher incidence in our study compared to that of Tartaglia et al. (2009) is not surprising given that our study focused on infertile males. The pathogenesis of this rare karyotype is complicated and may result from the nondisjunction of primary spermatocyte in meiosis I followed by the nondisjunction of sister chromatids in meiosis II or from the combination of an aneuploidy gamete derived from nondisjunction of secondary spermatocytes and maternal secondary oocytes (Kleiman et al., 1999).

Sex reversal syndrome (SRS) is a disease of gonadal sex and chromosomal sex inconsistency (Rajender et al., 2006). SRS can be divided into 46, XX male SRS and 46, XY female SRS. In humans, XX maleness occurs with an incidence of approximately 1 in every 20,000-30,000 male births (Ergun-Longmire et al., 2005; Rajender et al., 2006; Vorona et al., 2007). The incidence in the infertile men in our study was $1.57 \%$ above average. We identified 8 patients with SRS who were phenotypically male with infertility and small testes. This phenotype may result from the expression of the SRY gene or upregulated expression of genes in the SOX family (Alves et al., 2010).

The analysis of 810 patients with OA, OS, and OAT revealed that the prevalence of chromosomal abnormality and AZF deletion was 13.58\% (cf.; 14.5\%, Retief et al., 1984; 15.4\%, Bourrouillou et al., 1985) and 4.94\% (c.f.; 5-10\%, Zhu et al., 2008), respectively, as shown in Table 3. The frequency of abnormal karyotype with AZF deletion was $1.85 \%$ lower than that in a study by Devroey et al. (2009), who reported 3.68\% (see Table 3). The analysis for microdeletions revealed that sY254 and sY255 in AZFc were the most common deletion sites (Table 4). On the contrary, a study by Li et al. (2012) in populations of northern Chinese has shown that AZFa and AZFb display deletion rates higher than that in AZFc. More samples should be studied to confirm this difference.

\begin{tabular}{|c|c|c|c|}
\hline & Chromosomal abnormality & AZF deletion & Chromosomal abnormality + AZF deletion \\
\hline $\mathrm{N}$ & 110 & 40 & 15 \\
\hline Ratio (\%) & 13.58 & 4.94 & 1.85 \\
\hline
\end{tabular}

Six STSs include sY86 and USP9Y in AZFa; sY127 and sY134 in AZFb; sY254 and sY255 in AZFc.

\begin{tabular}{|c|c|c|c|c|c|c|c|}
\hline \multirow[t]{2}{*}{ Case No. } & \multicolumn{2}{|c|}{ AZFa } & \multicolumn{2}{|c|}{$\mathrm{AZFb}$} & \multicolumn{2}{|c|}{ AZFc } & \multirow[t]{2}{*}{ SRY } \\
\hline & sY86 & $\overline{\text { USP9Y }}$ & sY127 & sY134 & sY254 & sY255 & \\
\hline 1 & $\mathbf{\Delta}$ & & & & & & + \\
\hline 6 & $\bar{\Delta}$ & $\Delta$ & & & & & + \\
\hline 2 & & & $\Delta$ & $\Delta$ & & & + \\
\hline 22 & & & & & $\Delta$ & $\Delta$ & + \\
\hline 2 & & & $\Delta$ & $\Delta$ & $\bar{\Delta}$ & $\bar{\Delta}$ & + \\
\hline 5 & $\Delta$ & $\Delta$ & $\Delta$ & $\bar{\Delta}$ & $\Delta$ & $\Delta$ & + \\
\hline 2 & $\bar{\Delta}$ & $\overline{\mathbf{A}}$ & $\bar{\Delta}$ & $\overline{\mathbf{A}}$ & $\overline{\mathbf{A}}$ & $\overline{\mathbf{A}}$ & - \\
\hline Total number & 14 & 13 & $\overline{11}$ & 11 & 31 & 31 & 2 \\
\hline
\end{tabular}

$\Delta$ and blank cells mean absence or presence of AZFs region, respectively; (+) and (-) mean positive and negative of SRY, respectively. 
We identified 55 patients with $\mathrm{Y} \geq 18$ Chromosome and 49 patients with $\mathrm{Y} \leq 21$ Chromosome, which accounted for $2.05 \%$ of all patients in our study population. These variations in the $\mathrm{Y}$ chromosome may result in chromosomal instability and increase the risk of deletions in AZF regions in these patients.

The main autosomal variations in the study population included balanced translocations, Robertsonian translocation, increased satellites, increased secondary constriction, deletion, duplication, and inversion. These variations were found in 98 patients. Generally, these changes greatly alter chromosome structure, which may affect a large number of genes; therefore, they often result in AS, OS, OAT, infertility, and habitual abortion (Huang et al., 2012) or, more severely, lead to life-threatening disorders in development and metabolism.

In conclusion, the causation of male infertility is complicated. Chromosomal aberration, microdeletion in the AZF region, and deletion of sex-determined genes may play essential roles. Currently, the primary ART for male infertility is intracytoplasmic sperm injection/in vitro fertilization. However, these techniques remain risky if the genetic backgrounds of infertile patients are unclear. Therefore, combining ART and other techniques such as fluorescence in situ hybridization and primed in situ labeling to detect chromosomal aberration and gene deletion is essential for those who have family members with serious genetic disorder and are seeking reproductive assistance from ART (Tournaye et al., 1996; Van Assche et al., 1999).

\section{REFERENCES}

Alves C, Braid Z, Coeli FB and Mello MP (2010). 46,XX male - testicular disorder of sexual differentiation (DSD): hormonal, molecular and cytogenetic studies. Arq. Bras. Endocrinol. Metabol. 54: 685-689.

Bourrouillou G, Dastugue N and Colombies P (1985). Chromosome studies in 952 infertile males with a sperm count below 10 million/ml. Hum. Genet. 71: 366-367.

Devroey P, Fauser BC and Diedrich K (2009). Approaches to improve the diagnosis and management of infertility. Hum. Reprod. Update 15: 391-408.

Ergun-Longmire B, Vinci G, Alonso L, Matthew S, et al. (2005). Clinical, hormonal and cytogenetic evaluation of 46,XX males and review of the literature. J. Pediatr. Endocrinol. Metab. 18: 739-748.

Guichaoua MR, Delafontaine D, Noel B and Luciani JM (1993). L'infertilitè masculine d'origine chromosomique. Contracept Fertil Sex. 21: 113-121.

Huang J, Lian Y, Qiao J and Liu P (2012). Clinical characteristics and preimplantation genetic diagnosis for male Robertsonian translocations. Beijing Da. Хue. Хue. Bao. 44: 544-546.

Kleiman SE, Yogev L, Gamzu R, Hauser R, et al. (1999). Genetic evaluation of infertile men. Hum. Reprod. 14: 33-38.

Lanfranco F, Kamischke A, Zitzmann M and Nieschlag E (2004). Klinefelter's syndrome. Lancet 364: 273-283.

Li D, Zhang H, Wang R, Zhu H, et al. (2012). Chromosomal abnormalities in men with pregestational and gestational infertility in northeast China. J. Assist. Reprod. Genet. 29: 829-836.

Mitra A, Dada R, Kumar R, Gupta NP, et al. (2006). Y chromosome microdeletions in azoospermic patients with Klinefelter's syndrome. Asian J. Androl. 8: 81-88.

Rajender S, Rajani V, Gupta NJ, Chakravarty B, et al. (2006). SRY-negative 46,XX male with normal genitals, complete masculinization and infertility. Mol. Hum. Reprod. 12: 341-346.

Retief AE, Van Zyl JA, Menkveld R, Fox MF, et al. (1984). Chromosome studies in 496 infertile males with a sperm count below 10 million/ml. Hum. Genet. 66: 162-164.

Reubinoff BE, Abeliovich D, Werner M, Schenker JG, et al. (1998). A birth in non-mosaic Klinefelter's syndrome after testicular fine needle aspiration, intracytoplasmic sperm injection and preimplantation genetic diagnosis. Hum. Reprod. 13: 1887-1892.

Staessen C, Tournaye H, Van Assche E, Michiels A, et al. (2003). PGD in 47,XXY Klinefelter's syndrome patients. Hum. Reprod. Update 9: 319-330.

Tartaglia N, Borodyanskaya M and Hall DA (2009). Tremor in 48,XXYY syndrome. Mov. Disord. 24: 2001-2007.

Tournaye H, Staessen C, Liebaers I, Van Assche E, et al. (1996). Testicular sperm recovery in nine 47,XXY Klinefelter patients. Hum. Reprod. 11: 1644-1649. 
Van Assche E, Bonduelle M, Tournaye H, Joris H, et al. (1996). Cytogenetics of infertile men. Hum. Reprod. 11 (Suppl 4): 1-24. Van Assche E, Staessen C, Vegetti W, Bonduelle M, et al. (1999). Preimplantation genetic diagnosis and sperm analysis by fluorescence in-situ hybridization for the most common reciprocal translocation t(11;22). Mol. Hum. Reprod. 5: 682-690.

Vorona E, Zitzmann M, Gromoll J, Schuring AN, et al. (2007). Clinical, endocrinological, and epigenetic features of the 46,XX male syndrome, compared with 47,XXY Klinefelter patients. J. Clin. Endocrinol. Metab. 92: 3458-3465.

Zhu YJ, Liu SY, Wang H, Wei P, et al. (2008). The prevalence of azoospermia factor microdeletion on the Y chromosome of Chinese infertile men detected by multi-analyte suspension array technology. Asian J. Androl. 10: 873-881. 